\title{
MOBILE APPLICATION PROJECT FOR SHARING INSTANTANEOUS\& LOCATION BASED PHOTOGRAPHS FOR MAKING ENVIRONMENTAL MONITORING MORE EFFECTIVE IN TURKEY \#
}

\author{
Ertugrul Esmeray $^{1^{*},}$, Sinan Savas ${ }^{2}$ \\ ${ }^{1}$ Karabuk University, Environmental Engineering Department, Karabuk, Turkey; \\ ${ }^{2}$ Karabuk University Institute of Natural Sciences Department of Environmental Engineering, Karabuk, Turkey; \\ *Corresponding author: Ertugrul Esmeray ${ }^{1 *}$, email: eesmeray@karabuk.edu.tr;
}

Received May, 2018; Accepted June, 2018; Published July, 2018;

DOI: https://doi.org/10.31407/ijees8411

UOI license: http://u-o-i.org/1.01/ijees/42029205

\begin{abstract}
Environmental pollution and related problems are the first ones among the problems that humankind need to worry because of their results and the need to find immediate solutions. For preventing and monitoring environmental pollution, traditional ways such as denunciation lines are lacking efficiency. As technology got developed and used more widely, smartphones and mass communication terms got more into our lives. As an alternative to the existing methods in order to prevent and fight environmental pollution; a mobile application that lets people to share environmental pollution with photographs by providing time and location information. It was aimed to build a bridge between the prevention of and fighting against environmental pollution and to make mass fights possible. By using the mobile application, people can take pictures of "environmental pollution" acts, can add comments and captions then share with authorized bodies and other users. After sharing, pictures are stored in the cloud system and via the web interface that we created, authorized local bodies can see those acts with the location and time information, on a map. With this application, environmental pollution acts can be monitored 24/7, immediately.
\end{abstract}

Key words: Environmental Monitoring; Mobile Software; Environmental Pollution 